\author{
M E T A M O R F O S A \\ Journal of Biological Sciences \\ elSSN: 2655-8122 \\ http://ojs.unud.ac.id/index.php/metamorfosa
}

\title{
Penggunaan Habitat oleh Elang Brontok, Elang Ular Bido dan Elang Laut Perut Putih di Taman Wisata Alam Danau Buyan-Danau Tamblingan dan Sekitarnya
}

\section{Habitat Use by Changeable hawk-eagle, Crested serpent-eagle and White bellied sea-eagle at Nature Recreation Park of Lake Buyan and Lake Tamblingan and Surrounding Area}

\author{
Fathur Rohman ${ }^{1 *}$, I Ketut Ginantra ${ }^{2}$, A. A. Gde Raka Dalem ${ }^{2}$ \\ ${ }^{1}$ Balai Konservasi Sumber Daya Alam Bali \\ ${ }^{2}$ Program Studi Biologi Fakultas MIPA, Universitas Udayana \\ *Email: fathur1st@gmail.com
}

\section{INTISARI}

Penelitian bertujuan untuk mengetahui preferensi habitat oleh elang brontok (Nisaetus cirrhatus), elang ular bido (Spilornis cheela) dan elang laut perut putih (Halliaeetus leucogaster) di Taman Wisata Alam (TWA) Danau Buyan-Danau Tamblingan dan sekitarnya sejak Pebruari - Juli 2016. Pengumpulan data pengamatan di lapangan menggunakan metode "pengamatan ke bawah" (look down method) dan "pengamatan ke atas" yang dipadukan dengan penempatan sembilan titik pengamatan. Data pengamatan dilakukan analisis dengan menggunakan metode principle component analysis (PCA). Hasil penelitian menunjukkan bahwa elang brontok lebih menyukai tipe habitat hutan primer, hutan terfragmentasi, hutan sekunder dan hutan tanaman. Elang ular bido lebih menyukai tipe habitat hutan primer, lahan pertanian, pemukiman dan hutan rakyat. Elang laut perut putih menyukai tipe habitat hutan primer dan tipe habitat lahan basah.

Kata kunci : burung pemangsa, elang, tipe habitat, habitat preferensi, Danau Buyan-Danau Tamblingan.

\begin{abstract}
Research on the habitat preferrence by Changeable hawk-eagle (Nisaetus cirrhatus) (CHE), Crested serpent-eagle (Spilornis cheela) (CSE), and White bellied sea-eagle (Haliaeetus leucogaster) (WSE) was conducted at Nature Recreation Park of Lake Buyan and Lake Tamblingan and Surrounding area between February and July, 2016. Data collection was conducted through field observation using the "look down method" and the "look up method" combined with placement of observation points. Data collection was analysed by principle component analisys (PCA) method. Research results related to preferenced habitat were as follows: (1) the CHE prefered fragmented forest, secondary forest, and cultivated forest types habitat. (2) The CSE prefered habitat types of farming land, residence, and sosial forest. (3) The WSE prefered just one habitat type, that was the wet land habitat type.
\end{abstract}

Keywords: eagle, raptor, forest, habitat, habitat preference, Buyan lake-Tamblingan lake 


\section{PENDAHULUAN}

Kelompok burung pemangsa di Indonesia terdapat 69 jenis yang termasuk dalam ordo Accipitriformes, tujuh famili yaitu Accipitridae, Falconidae, Sagittaridae, Cathartidae, Strigidae, Pandionidae dan Tytonidae (Prawiradilaga et al. 2002). Sebelas jenis diantaranya sangat terancam bahkan dalam kondisi kritis, sebelas jenis tersebut yaitu elang jawa (Nisaetus bartelsi), elang flores (Nisaetus floris), elang wallasea (Nisaetus nanus), elang ular bawean (Spilornis baweanus), elang ikan kepala kelabu (Ichtyophapa ichthyaetus), elang ikan kecil (Ichthyophapa humilis), elang alap kecil (Accipiter nanus), rajawali papua (Harpyopsis novaeguineae), rajawali totol (Aquila clanga), rajawali kuskus (Aquila gurneyi) dan elang alap doria (Megatriorchis doriae). Semua jenis dari famili Pandionidae dan famili Accipitridae merupakan jenis yang dilindungi (Permen LHK Nomor: P.106/MENLHK/SETJEN/KUM.1/12/ 2018). Tiga jenis elang yaitu Elang Laut Perut Putih (Haliaeetus leucogaster), Elang Brontok (Nisaetus cirrhatus) dan Elang Ular Bido (Spilornis cheela) termasuk dalam appendix II daftar CITES (CITES, 2017), artinya bahwa jenis tersebut tidak dalam kategori terancam punah namun memiliki peluang untuk terancam punah jika kegiatan perdagangannya tidak diawasi dengan ketat.

Kawasan TWA Danau Buyan-Danau Tamblingan didominasi tumbuhan diantaranya rasamala (Altingia exelsa), cemara geseng (Casuarina junghuniana), beringin (Ficus sp.), belantih (Homalanthus giganteus), lateng (Laportea sp.), dan gintungan (Bischofia javanica) (BKSDA Bali, 2013). Hal tersebut terlihat banyak temuan bekas gigitan buah pada lantai hutan, jenis-jenis tersebut merupakan pohon pakan bagi berbagai satwa mangsa elang. Selama pengumpulan data di lapangan, jenis satwa yang terlihat memakan buah dari jenis pohon tersebut yaitu tupai dan beberapa jenis burung. Keberadaan beberapa jenis ikan di tiga danau yaitu Beratan, Buyan dan Tamblingan menjadi habitat yang penting bagi berbagai jenis satwa liar termasuk diantaranya adalah elang brontok (Nisaetus cirrhatus), elang laut perut putih (Haliaeetus leucogaster) dan elang ular bido (Spilornis cheela). Hal ini didukung oleh Icshan (2006) yang menyatakan bahwa TWA Danau Buyan-Danau Tamblingan menjadi habitat beberapa jenis burung elang. Ketiga jenis elang tersebut merupakan jenis yang umum dijumpai di kawasan TWA Danau Buyan dan Danau Tamblingan.

Fokus pada penelitian ini adalah menentukan tipe habitat yang disukai oleh elang brontok, elang ular bido dan elang laut perut putih di TWA Danau Buyan-Danau Tamblingan dan sekitarnya. Hasil penelitian ini dapat dijadikan acuan penentuan kebijakan dalam pengelolaan kawasan sebagai salah satu upaya pelestarian spesies langka di habitat alaminya (in-situ).

\section{BAHAN DAN METODE}

Penelitian dilakukan dari bulan Februari Juli 2016 di Kawasan TWA Danau Buyan dan Danau Tamblingan dan sekitarnya. Pengamatan dilakukan mulai pada jam 08.00 - 18.00 wita di sembilan titik pengamatan pada 8 tipe habitat yaitu hutan primer, hutan terfragmentasi, hutan sekunder, hutan tanaman, hutan rakyat, wilayah pertanian, wilayah permukiman dan tipe habitat lahan basah. Titik pengamatan ditunjukkan pada Gambar 1.

Metode yang digunakan untuk mengamati aktivitas elang Ad-Libithum Sampling Method (Altman, 1973), yaitu dengan mencatat sebanyak mungkin aktivitas tiga jenis (species) burung pemangsa yang dijumpai yaitu aktivitas terbang, bertengger dan berburu. Metode ini dikombinasikan dengan metode "pengamatan ke bawah" (look down method) (Thiollay, 1996) dan "pengamatan ke atas".

Penggunaan habitat oleh tiga jenis elang ditentukan berdasarkan frekwensi kehadiran jenis-jenis elang pada masing-masing tipe habitat. Hubungan preferensi habitat yang didasarkan pada aktivitas burung elang di tiap tipe habitat dilakukan analisis multivarian menggunakan teknik PCA (Principal Component Analysis) (Fardila dan Sjarmidi, 2012; Ludwig and Reynolds, 1988) menggunakan software analisis statistik XLSTAT 2015.03 dari Thierry Fahmy, Addinsoft, Perancis dan California. 


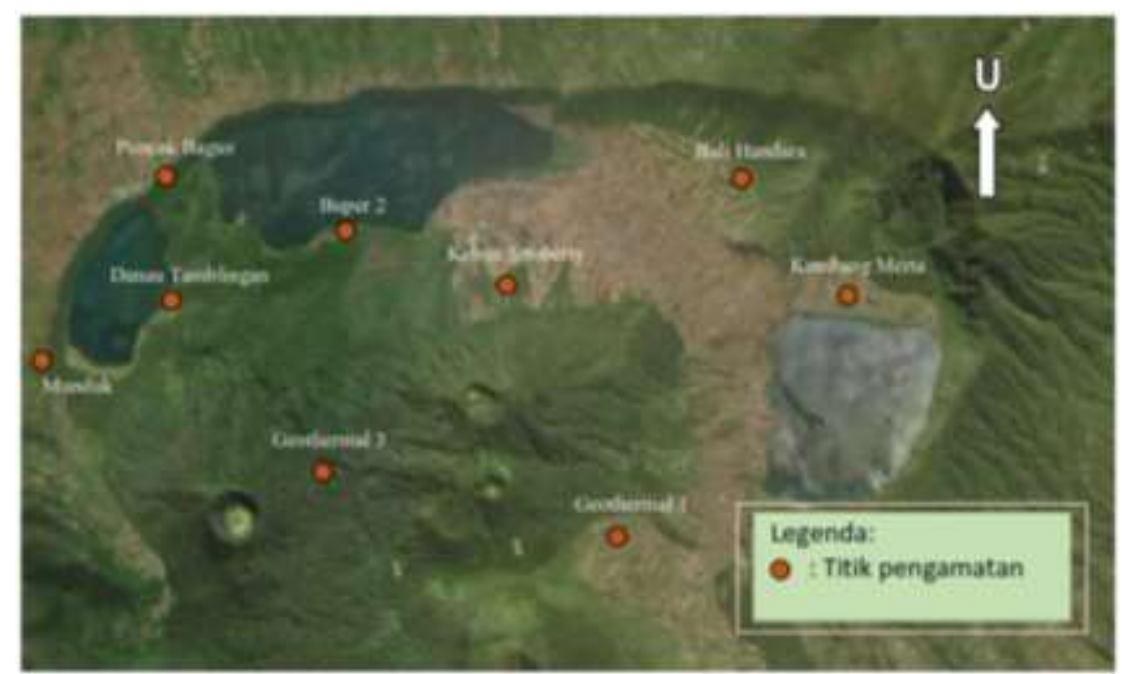

Gambar 1. Peta lokasi penelitian di TWA Danau Buyan - Danau Tamblingan dan sekitarnya (modifikasi Google Earth, 2016).

\section{HASIL DAN PEMBAHASAN}

Selama penelitian telah dilakukan 27 kali pengamatan terhadap tiga jenis elang target, 26 kali pengamatan $(96,29 \%)$ diantaranya berhasil ditemukan dan 1 kali pengamatan $(3,7 \%)$ lainnya tidak ditemukan. Penelitian ini hanya fokus pada tiga jenis elang dan mengabaikan perjumpaan dengan jenis elang lainnya. Data dari 26 kali pengamatan tercatat sebanyak 110 kali $(45 \%)$ terjadi pada jenis elang brontok (Nisaetus cirrhatus), sebanyak 86 kali (35\%) terjadi pada elang ular bido (Spilornis cheela) dan sebanyak 49 kali (20\%) terjadi pada elang laut perut putih (Haliaeetus leucogaster) seperti yang disajikan pada Tabel 1.

\section{Tabel 1. Data perjumpaan tiga jenis elang di beberapa tipe habitat}

\begin{tabular}{|c|c|c|c|}
\hline Tipe Habitat & $\begin{array}{c}\text { Changeable hawk-eagle } \\
\text { (CHE) } \\
\text { Nisaetus cirrhatus } \\
\text { (\% total pengamatan) }\end{array}$ & $\begin{array}{c}\text { Crested serpent-eagle } \\
\text { (CSE) } \\
\text { Spilornis cheela } \\
\text { (\% total pengamatan) }\end{array}$ & $\begin{array}{l}\text { White bellied sea-eagle } \\
\text { (WSE) } \\
\text { Haliaeetus leucogaster } \\
\text { (\% total pengamatan) }\end{array}$ \\
\hline Pemukiman & $2(2)$ & $9(10,5)$ & $1(2)$ \\
\hline Lahan Pertanian & $6(5,5)$ & $12(14)$ & $4(8)$ \\
\hline Hutan Tanaman & $12(11)$ & $2(2,5)$ & $6(12)$ \\
\hline Hutan Terfragmen & $6(5,5)$ & $1(1)$ & $0(0)$ \\
\hline Hutan Sekunder & $24(22)$ & $6(7)$ & $5(10)$ \\
\hline Hutan Primer & $52(47)$ & $45(52)$ & $16(33)$ \\
\hline Hutan Rakyat & $7(6)$ & $11(13)$ & $1(2)$ \\
\hline Lahan Basah & $1(1)$ & $0(0)$ & $16(33)$ \\
\hline Total & 110 & 86 & 49 \\
\hline
\end{tabular}

Berbeda dengan hasil penelitian Widiana, (2007) yang menyatakan bahwa dari tiga jenis elang yang diteliti, jenis yang mendominasi/lebih sering dijumpai di kawasan Panaruban Tangkuban Perahu adalah elang hitam (Ichtynaetus malayensis) dibanding elang brontok dan elang ular bido. Lebih lanjut hal tersebut diduga karena elang hitam merupakan salah satu jenis burung pemangsa yang memiliki toleransi yang relatif tinggi terhadap penyusutan hutan dan mampu hidup pada sisasisa hutan yang di sekelilingnya telah 
dieksploitasi menjadi kawasan yang terbuka. Tingginya persentase perjumpaan terhadap tiga jenis elang tersebut sejalan dengan hasil penelitian Icshan (2006) yang menyatakan bahwa ketiga jenis elang tersebut mempunyai skala kelimpahan yang tinggi dibandingkan dengan jenis burung pemangsa lainnya di kawasan TWA Danau Buyan-Danau Tamblingan. Kondisi hutan yang masih baik dengan tipe habitat hutan primer dengan keanekaragaman tumbuhan yang tinggi dan didominasi dengan vegetasi pepohonan tinggi sangat dimungkinkan tersedianya satwa mangsa sehingga burung pemangsa sering mengunjungi kawasan tersebut untuk berburu, bertengger dan mengawasi mangsa.

MacKinnon et al. (1998) berpendapat bahwa kebiasaan burung pemangsa sering mengunjungi tepian hutan atau perbatasan daerah terbuka untuk berburu mangsa. Studi lain yang mendukung pendapat ini yaitu yang dilakukan oleh Ueta dan Minton (1996) dan Gokula (2012) yang menyatakan bahwa burung pemangsa menyukai pohon yang terbuka dan tertinggi dipinggiran hutan untuk bertengger.

Menurut Bengen (2000) hasil suatu analisis komponen utama dilakukan secara berbeda untuk variabel (jenis/spesies) dan individu (unit sampel/plot). Koordinat variable untuk setiap sumbu adalah sama dengan korelasi antara variable dan sumbu. Semakin kuat korelasi (negatif atau positif) maka semakin dekat variable tersebut pada sumbu. Kedekatan (proksimitas) antar plot menunjukan kemiripan ciri plot terhadap jenis, sedangkan sudut yang terbentuk antara sumbu-sumbu jenis menunjukkan hubungan (korelasi). Pembentukan sudut sekitar 90-180 derajat menunjukkan keduanya tidak mempunyai hubungan dalam sebarannya dalam sampel.

Preferensi habitat oleh tiga jenis elang dilustrasikan dalam diagram PCA (Principal Component Analysis) yang ditunjukkan pada Gambar 2. Model analisis ini didasarkan pada parameter frekuensi prilaku pada tipe habitat ditemukannya aktivitas harian suatu jenis elang. Analisis PCA penggunaan habitat tiga jenis elang pada berbagai tipe habitat menunjukkan kontribusi masing-masing sumbu sebesar
$54,72 \%$ untuk sumbu 1 dan $45,28 \%$ untuk sumbu 2 dari ragam total sebesar $100 \%$. Lebih lanjut analisis PCA sesuai dengan Gambar 2 menunjukkan adanya kelompok titik yang memiliki kecenderungan karakteristik yang sama karena terletak pada axis yang sama.

Kelompok yang pertama yaitu titik yang terdiri dari tipe habitat hutan terfragmentasi, hutan sekunder dan hutan tanaman yang berdekatan dengan titik dari Elang Brontok. Hal itu berarti elang brontok mempunyai korelasi yang kuat dengan tipe-tipe habitat tersebut. Kelompok kedua yaitu titik yang terdiri dari tipe habitat lahan pertanian, pemukiman dan hutan rakyat yang berdekatan dengan titik elang ular serta kelompok ketiga yang hanya terdapat satu tipe habitat yaitu tipe habitat lahan basah yang eksklusif hanya berdekatan dengan elanglaut perut-putih.

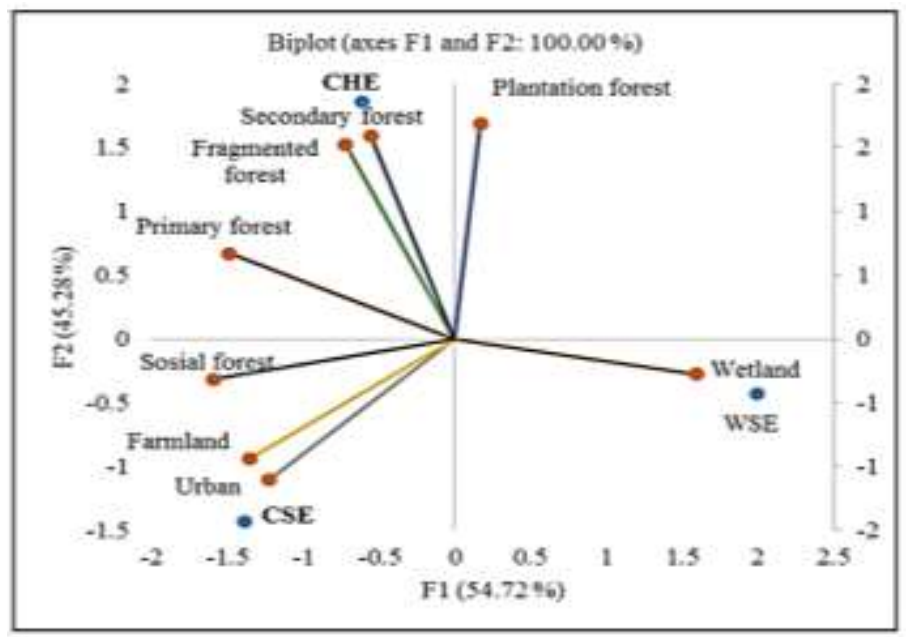

Gambar 2. Preferensi habitat oleh tiga jenis elang Keterangan: CHE : Elang Brontok; CSE : Elang Ular; WSE : Elang Laut

Berdasarkan diagram pada Gambar 2, menunjukkan bahwa elang brontok sangat menyukai atau tergantung terhadap tipe habitat hutan primer, hutan sekunder, hutan tanaman dan tipe habitat hutan terfragmentasi. Penelitian Nijman (2004) menyatakan bahwa tujuh tipe habitat yang diteliti di seluruh Pulau Jawa, elang brontok ditemukan pada semua tipe habitat. Sejalan dengan hasil penelitian penggunaan habitat oleh burung pemangsa di Provinsi Sulawesi Tengah, bahwa jumlah ratarata perjumpaan individu raptor terbanyak 
tercatat pada tipe hutan bervegetasi rapat yaitu elang genus Nisaetus yaitu elang sulawesi (Nisaetus lanceolatus), lahan basah didominasi oleh elang-ikan kepala-kelabu (Ichthyophaga ichthyaetus), tipe habitat lahan pertanian didominasi oleh alap-alap sapi (Falco moluccensis), perkebunan dan hutan terfragmentasi didominasi oleh sikep-madu sulawesi (Pernis celebensis) (Tapia dan Rahman, 2001). Informasi lain yang didapat dari wawancara dengan masyarakat sekitar, bahwa elang brontok pernah dijumpai bersarang di pohon-pohon besar jenis cemara geseng di lereng bukit.

\section{Elang Brontok (Nisaetus cirrhatus)}

Diagram PCA komponen 1 dan 2 pada Gambar 3 menunjukkan secara khusus aktivitas harian elang brontok terhadap beberapa tipe habitat yang ada di kawasan TWA Danau Buyan-Danau Tamblingan dan sekitarnya. Diagram tersebut menjelaskan bahwa aktivitas gliding dan soaring dilakupan hampir di semua tipe habitat, sedangkan aktivitas diving yang hanya ekslusif pada tipe habitat lahan basah (wetland).

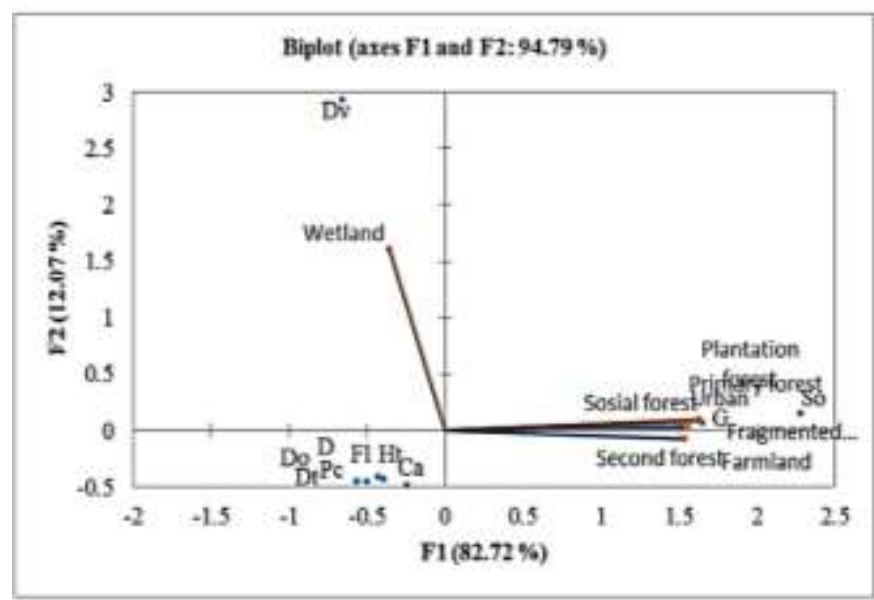

Gambar 3. Preferensi habitat elang brontok berdasarkan aktivitas harian.

Keterangan: Dv: Diving, Do: Display dengan spesies lain, D: display/undulating, Dt: display talond, Ca: calling, Ht: hunting, G: gliding, So: soaring, Fl: flapping, Pc: perching.

Aktivitas terbanyak yang dijumpai pada saat pengamatan di lapangan adalah soaring, hal ini karena aktivitas soaring adalah salah satu cara mempertahankan atau melindungi teritori dari predator atau kompetitornya. Teritori elang biasanya adalah kawasan hutan primer atau hutan sekunder, kedua kawasan tersebut merupakan kawasan yang mempunyai ekosistem yang masih alami dan mempunyai keanekaragaman hayati yang tinggi dan tentunya menyediakan sumber makanan bagi kelompok burung pemangsa (Indrawan dkk., 2012). Pendapat yang sama oleh Ichsan (2006) ditemukannya aktivitas soaring di beberapa tipe habitat di luar areal hutan seperti lahan pertanian atau daerah pemukiman, hal tersebut erat kaitanya dengan karakter elang sebagai predator yang melakukan perburuan mangsa, areal yang terbuka memudahkan elang melakukan pengawasan dan menangkap mangsa.

\section{Elang Ular Bido (Spilornis cheela)}

Menurut Widiana (2007) elang ular melakukan aktivitas terbang di empat tipe habitat sedangkan aktivitas bertengger dan berburu hanya dilakukan di habitat perkebunan teh. Analisis PCA aktivitas elang ular pada berbagai tipe habitat menunjukkan informasi penting pada dua komponen utama (F1 dan F2) dengan kontribusi sebesar $84,06 \%$ untuk komponen (F1) dan 15, $11 \%$ untuk komponen (F2) dari ragam total sebesar 99,18\% seperti disajikan pada Gambar 4.

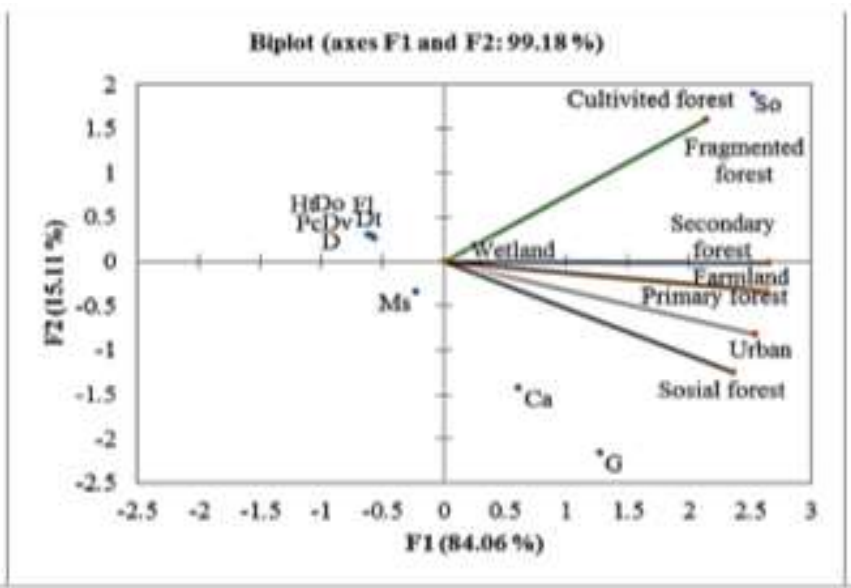

Gambar 4. Preferensi habitat oleh elang ular berdasarkan aktivitas.

Keterangan: Dv: Diving, Do: Display dengan spesies lain, D: display/undulating, Dt: display talond, Ca: calling, Ht: hunting, G: gliding, So: soaring, Fl: flapping, Pc: perching. 
Diagram PCA komponen 1 dan 2 pada Gambar 4 menunjukkan secara khusus aktivitas harian elang ular terhadap beberapa tipe habitat yang ada lokasi penelitian. Diagram tersebut menjelaskan bahwa aktivitas soaring berhubungan erat dengan semua tipe habitat artinya elang ular hampir melakukan aktivitas mencari dan mengawasi mangsa atau mempertahankan teritorinya disemua tipe habitat, namun demikian tipe hutan terfragmentasi dan hutan tanaman adalah dua tipe habitat yang sangat berpengaruh besar atau memiliki korelasi positif terhadap aktivitas soaring, tetapi berbeda dengan aktivitas mutual soaring yang memiliki korelasi negatif dengan tipe habitat hutan tanaman dan hutan terfragmentasi.

Aktivitas calling dan gliding sangat dipengaruhi oleh beberapa tipe habitat yaitu hutan sekunder, hutan primer, lahan pertanian, pemukiman dan hutan rakyat. Sedangkan aktivitas berburu, tengger, flapping, display talond, undulating dan display dengan sepesies lain memiliki korelasi negatif dengan tipe habitat pemukiman dan hutan rakyat. Hal ini diduga bahwa daerah penyangga kawasan yang berupa lahan pertanian sudah terlalu banyak aktivitas manusia berupa penggunaan pestisida yang membuat elang ular cenderung menjauhi tipe habitat tersebut. Secara umum elang ular menyukai terhadap habitat yang cenderung terbuka, hal ini berbeda dengan Sawitri dan Takandjandji (2010) yang menyatakan bahwa sifat elang ular sangat sensitif terhadap kehadiran manusia.

Pemilihan habitat yang terbuka karena reptil paling banyak dijumpai di tutupan lahan budidaya. Menurut Purbahapsari (2013) reptil banyak dijumpai pada pagi hari, saat melakukan aktivitas berjemur (busking). Ketika berjemur, reptil berada pada daerah terbuka yang terpapar sinar matahari secara langsung. Pada kondisi demikian memungkinkan elang mudah mendeteksi keberadaan mangsanya. Perubahan sistem pertanian dari perkebunan kopi menjadi tanaman hortikultura di lokasi penelitian yang cenderung banyak memakai pestisida, diduga mempercepat musnahnya beberapa satwa mangsa dari elang.

\section{Elang-laut leucogaster) \\ perut-putih}

(Halliaeetus

Analisis PCA biplot pada axis menunjukkan bahwa informasi penting terpusat dua kompunen utama (F1 dan F2) dengan kontribusi masing-masing komponen sebesar $43.33 \%$ untuk komponen (F1) dan $27.02 \%$ untuk komponen (F2) dari ragam total sebesar 70.36\%. Gambar 5 menunjukkan bahwa aktivitas elang-laut perut-putih tidak memiliki korelasi dengan tipe habitat hutan terfragmentasi. Aktivitas calling, soaring dan mutual soaring memiliki korelasi yang kuat terhadap keberadaan tipe habitat hutan sekunder, pemukiman, hutan tanaman dan hutan primer namun tipe habitat tersebut memiliki korelasi negatif terhadap aktivitas diving, display talond, display dengan spesies lain, berburu, undulating dan bertengger. Hal ini berarti bahwa Elang-laut perut-putih meskipun habitat aslinya adalah dominan di daerah perairan, tapi hasil analisis di atas menunjukkan memiliki ketergantungan terhadap tipe habitat bervegetasi diantaranya yaitu sebagai lokasi pembangunan sarang. Hal ini didukung oleh hasil komunikasi pribadi dengan masyarakat sekitar bahwa pernah ditemukan sarang aktif elang laut pada pohon beringin (Ficus sp.) di lereng bukit Mangu yang jaraknya tidak jauh dari aliran sumber mata air.

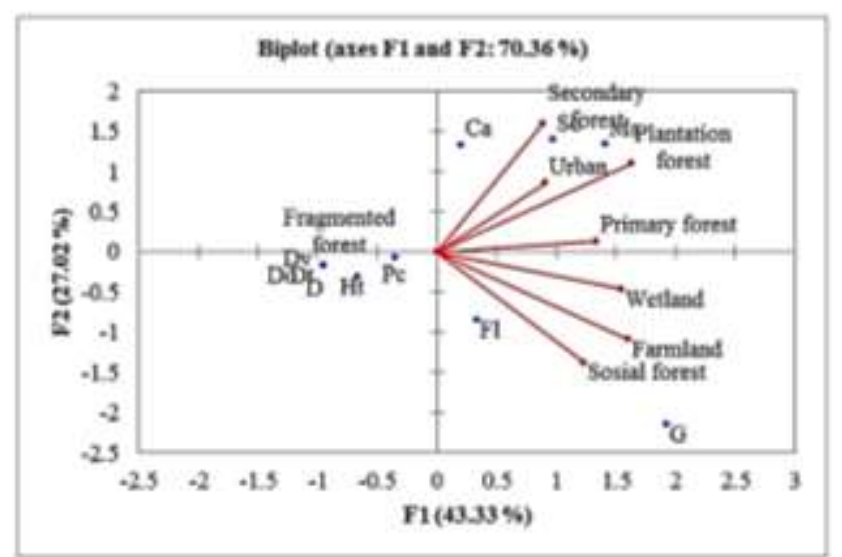

Gambar 5. Diagram kecenderungan preferensi habitat elang laut perut putih.

Keterangan: Dv: Diving, Do: Display dengan spesies lain, D: display/undulating, Dt: display talond, Ca: calling, Ht: hunting, G: gliding, So: soaring, Fl: flapping, Pc: perching. 
Menurut Soednjoto, dkk (2014) salah satu faktor yang menyebabkan suatu spesies sering dijumpai pada suatu habitat adalah kemampuan penyediaan pakan secara berkelanjutan, baik dari kuantitas maupun kualitas, serta menyediakan ruang yang nyaman untuk dapat mengekspresikan perilaku alaminya. Tipe habitat lahan pertanian, hutan tanaman, hutan primer dan khususnya tipe habitat lahan basah (wetland), tipe habitat tersebut menjadi lokasi yang sering digunakan untuk melakukan aktivitas terbang dan berburu/mencari makan, hal tersebut diduga karena Danau Buyan dan Danau Tamblingan merupakan habitat yang baik bagi beberapa jenis ikan diantaranya ikan zebra (Amatitlania nigrofasciata), mujair (Oreochromis mossambicus), tawes (Barbonymus gonionotus), nila (Oreochromis niloticus) dan ikan karper (Cyprinus carpio) (BKSDA Bali, 2013). Hal tersebut membuktikan bahwa tingkat ketergantungan elang laut terhadap sumber air dan hutan yang dalam kondisi baik sangat tinggi, disamping tetap memerlukan tipe habitat lainnya untuk mendukung kelangsungan hidupnya, karena elang tidak hanya semata bersarang, berburu tetapi juga memerlukan habitat untuk mengekspresikan prilaku alami lainnya seperti istirahat, berlindung yang tentunya memerlukan tipe habitat yang lebih spesifik. Pendapat yang sama disampaikan oleh Wiersma dan Richardson (2009) bahwa 95\% elang laut perut putih dijumpai mencari makan di sekitar perairan budidaya.

Aktivitas flapping dan gliding memiliki korelasi yang kuat terhadap keberadaan tipe habitat hutan rakyat, lahan pertanian dan habitat lahan basah. Aktivitas flapping biasanya banyak dilakuan oleh burung pemangsa di sekitar teritori dan sarang. Hal ini diduga bahwa pada saat membesarkan anak induk burung pemangsa tidak pergi jauh dari sarang dan cenderung agresif dan sangat protektif sehingga perlu melakukan pengamanan dan pengawasan sarang dari kompetitor dan predator disekitar sarang.

\section{KESIMPULAN}

Hasil analisis PCA menunjukkan bahwa Elang Brontok menyukai beberapa tipe habitat yaitu tipe habitat hutan primer, hutan terfragmentasi, hutan sekunder dan hutan tanaman. Elang Ular lebih menyukai beberapa tipe habitat yaitu tipe habitat hutan primer, lahan pertanian, pemukiman dan hutan rakyat. Sedangkan Elang Laut Perut Putih menyukai satu tipe habitat saja yaitu tipe habitat lahan basah.

Saran

Perlu penelitian lebih lanjut untuk mengetahui perbedaan pola penggunaan habitat pada musim berbiak dan tidak berbiak, saat musim hujan dan kemarau dan potensi daya dukung habitat terkait ketersediaan sumber pakan bagi keberlangsungan hidup komunitas burung pemangsa di kawasan TWA Danau Buyan-Danau Tamblingan dan sekitarnya.

\section{UCAPAN TERIMAKASIH}

Terima kasih disampaikan kepada Kepala Balai Konservasi Sumber Daya Alam Bali (BKSDA Bali) dan staf atas ijin dan bantuannya dalam penelitian di lapangan.

\section{DAFTAR PUSTAKA}

Altman, J. 1973. Observational Study of Behavior: Sampling Methods. Journal Behavior, 49: 227-267.

Bengen, D.G. 2000. Teknik Pengambilan Contoh dan Analisis Data Biofisik Sumberdaya Pesisir. Pusat Kajian Sumberdaya Pesisir dan Lautan, Institut Pertanian Bogor. Bogor.

BKSDA Bali. 2013. Informasi Kawasan Konservasi Propinsi Bali. KSDA Bali.

CITES, 2017. Convention On International Trade In Endangered Species Of Wild Fauna\&Flora: Appendices I, II, III UNEP.

Fardila, D and A. Sjarmidi. 2012. Bird Distribution Along Environmental Gradient in North Bandung, West Java. Pro Soc Biodiv Intl Conf. Vol.2 pp.190-198.

Gokula. V. 2012. Breeding Ecology of The Crested Serpent Eagle (Spilornis cheela Latham, 1790) (Aves: Accipitriformes: Accipitridae) in Kolli Hills, Tamil Nadu, India. Tabrobanica 4 (2): 77-82.

Icshan, A. K. 2006. Distribusi, Identifikasi dan Aktivitas Burung Pemangsa di Taman 
Wisata Alam Danau Buyan - Danau Tamblingan (Skripsi). Program Studi Ilmu Biologi, Universitas Udayana. Denpasar.

Indrawan, M., Primack, R. B dan Supriatna, J. 2007. Biologi Konservasi. Yayasan Obor Indonesia, Conservation InternationalIndonesia, Pusat Informasi Lingkungan Indonesia (PILI), Yayasan WWF. Jakarta.

Ludwig, J.A and J.F. Reynolds. 1988. Statistical Ecology: A Primer on Methods and Computing. A Wiley-Interscience Publication.

MacKinnon, J., K. Philips dan B.V. Ballen. 1998. Seri Panduan Lapangan. BurungBurung di Sumatera, Jawa, Bali dan Kalimantan. Puslitbang Biologi LIPI.

Nijman, V. 2004. Habitat segregation in two congeneric hawk-eagles (Spizaetus bartelsi and $S$. cirrhatus) in Java, Indonesia. Abstract. Journal of Tropical Ecology. University of Amsterdam. Cambridge University Press.

Peraturan Menteri Lingkungan Hidup dan Kehutanan No. P106 tahun 2018 tentang Perubahan Kedua Atas Peraturan Menteri Lingkungan Hidup dan Kehutanan Republik Indonesia No. P.20/MENLHK/ SETJEN/KUM.1/6/2018 tentang Jenis Tumbuhan dan Satwa Dilindungi.

Prawiradilaga, D.M., T. Muratte, A. Muzakkir, T. Inoue, Kuswandono, A.A. Supriatna, D. Ekawati, M.Y. Afianto, Hapsoro, T. Ozawa dan N. Sakaguchi. 2002. Panduan survey lapangan dan pemantauan burung-burung pemangsa. PT. Bina Megawarna. Jakarta.

Purbahapsari. A. F. 2013. Penggunaan Habitat Koridor Halimun Salak Oleh Elang Ular
Bido (Spilornis Cheela Latham, 1790) di Taman Nasional Gunung Halimun Salak (Skripsi). Institut Pertanian Bogor. Bogor. Sawitri, R dan M. Takandjandji. 2010. Pengelolaan dan Perilaku Burung Elang di Pusat Penyelamatan Satwa Cikananga, Sukabumi. Jurnal Penelitian Hutan dan Konservasi Alam III(3): 257-270. Pusat Penelitian dan Pengembangan Hutan dan Konservasi Alam.

Soendjoto, M.A., M.K. Riefani dan M.Zen. 2014. Penggunaan Tipe Habitat oleh Avifauna di Lingkungan PT Arutmin Indonesia NPLCT, Kotabaru, Kalimantan Selatan. Sain \& Matematika 3(1).

Tapia.J.M and Z. Rahman. 2001. The Raptor community of Central Sulawesi: Habitat Selection and conservation status. Biological Conservation 107 pp: 111-122.

Thiollay, M. J. 1996. Raptor in Human Landscape. Sumatera: Rain Forest Raptor Communities, The Conservation Value of Tradisional Agroforest.

Ueta, M and J. S. Minton. 1996. Habitat Preference of Crested Serpent Eagle In Southern Japan. Wild Bird Society Of Japan. J Raptor Res. 30(2): 99-100.

Widiana, A. 2007. Penggunaan Tipe-tipe Habitat Oleh Tiga Jenis Elang di Kawasan Panaruban Tangkuban Perahu Jawa Barat (Tesis). Program Studi Biologi. Institut Teknologi Bandung.

Wiersma. J. M. and A. Richardson. 2009. Foraging Of White-Bellied Sea-Eagles Haliaeetus Leucogaster In Relation To Marine Fish Farms In Tasmania. Corella: 2009, 33(3): 71-79. School of Zoology, University of Tasmania. 